\title{
THE EXPERIMENTAL ANALYSIS OF AN INNOVATIVE YIELDING METALLIC DAMPER
}

VASILE-MIRCEA VENGHIAC - Assistant Lecturer, PhD, „Gheorghe Asachi” Technical University of Iaşi, Faculty of Civil Engineering and Building Services, e-mail: venghiacmircea@tuiasi.ro

MIHAI BUDESCU - Professor, PhD, „Gheorghe Asachi” Technical University of Iaşi, Faculty of Civil Engineering and Building Services, e-mail: mbudescu@tuiasi.ro

\begin{abstract}
One of the most destructive natural phenomena is the earthquake. These events destroy lives, goods and disrupt human activities. For this reason the anti-seismic protection of buildings is a very important and of interest subject in Civil Engineering. In the case of structures with a low seismic energy dissipation capacity (for example steel frame structures with Slimdek composite floors), this problem becomes more complicated due to the requirement of dampers. In this paper an experimental study is presented regarding an innovative yielding metallic energy dissipation device, proposed by the author. An experiment is carried out on a shake table. By studying the results from the experiments and from the previous carried out numerical analysis we can conclude that this device provides a high anti-seismic protection for this type of structures.
\end{abstract}

Keywords: anti-seismic design; energy dissipative column; hysteresis; Slimdek; composite floor.

\section{Introduction}

Earthquakes are among the most destructive phenomena on Earth. The great destruction potential is due to the energy released by the earthquake, energy which can be thousands or tens of thousands larger than the energy released by an atomic bomb. Human lives and material assets are annually lost, also, activities and services for maintaining social relations are disturbed due to these phenomena. Thereby, seismic protection is a very important aspect in structural design and is a subject studied worldwide.

The anti-seismic design of structures provides certain performance criteria relating to the capacity of buildings to dissipate the seismic energy in a steady state and for as many motion cycles as possible. Current design theory is based on the acceptance of plastic zones occurrence in structural elements, but the design should be oriented so as to avoid structural collapse. Plastic zones, which in the case of bars become plastic hinges, have the ability to dissipate energy through various phenomena (e.g. friction, plastic deformation of steel). Plastic hinges are designed to develop only in the main beams, avoiding their occurrence in columns which obviously would facilitate the creation of collapse mechanisms within the structure.

In recent years other methods for energy dissipation appeared by placing special devices within the structure. These devices can be designed to overtake the motion given by the wind and also by the seismic action. Their use eliminates the need for repair and strengthening of structural elements damaged after major earthquakes. Their beneficial effects regarding energy dissipation made these devices to quickly spread worldwide, becoming an essential solution for seismic protection of structures.

Buildings whose resistance structure eliminates the occurrence of plastic hinges in beams create the necessity of dampers. Frame structures with Slimdek composite floors or with flat slabs are such cases. Slimdek floors are structural systems where the beams are embedded within the thickness of the slab. This is accomplished by resting the steel decking on the bottom flange of the beam, as shown in Figure 1 [1]. 
Slimdek composite floors were created and are used especially in Great Britain, where there are no earthquakes. In recent years, countries situated in seismic areas, such as New Zealand, have shown great interest in using these types of floors. This raises the problem of seismic energy dissipation within steel frame structures with such floors. The development of plastic hinges in beams is impossible due to the fact that they are encased in concrete. Thus, the behaviour of these floors to seismic actions is similar to that of flat slabs.

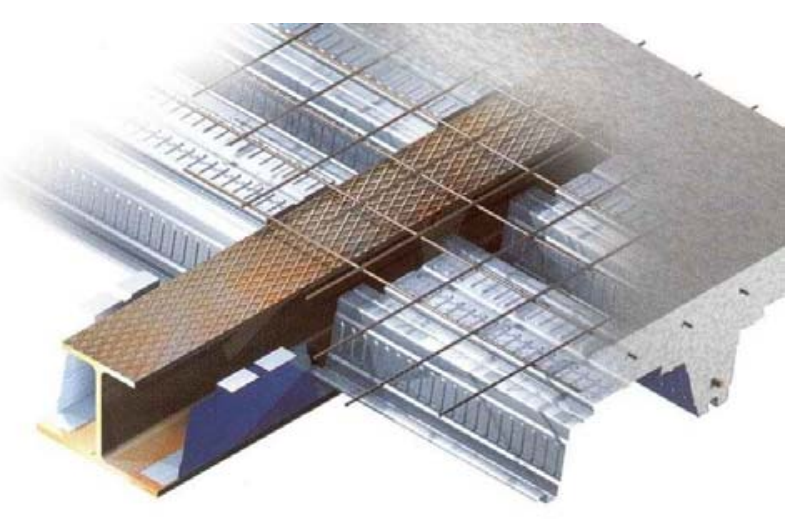

Fig. 1 - Slimdek composite floor [2].

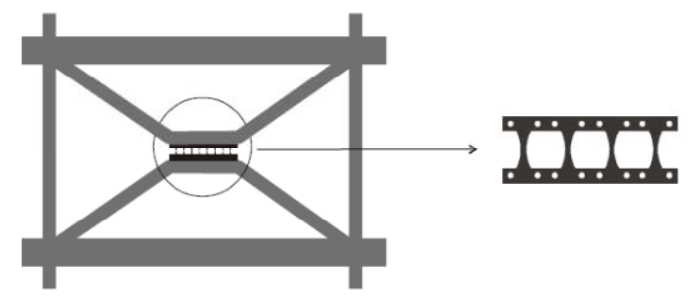

a.

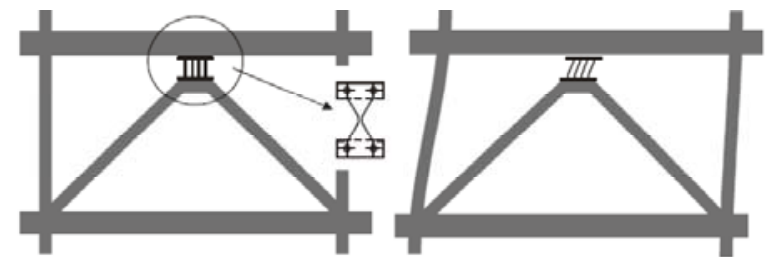

c.

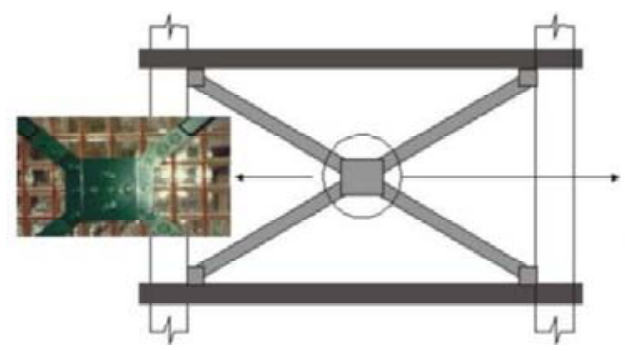

e.

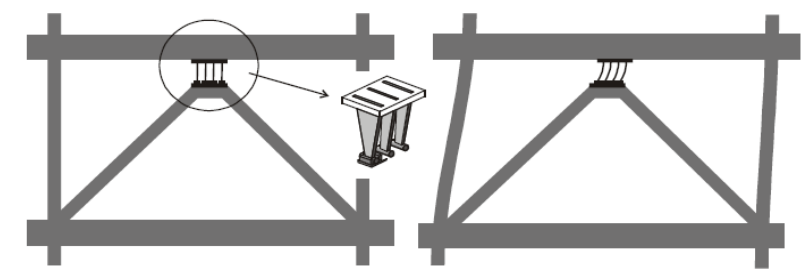

b.

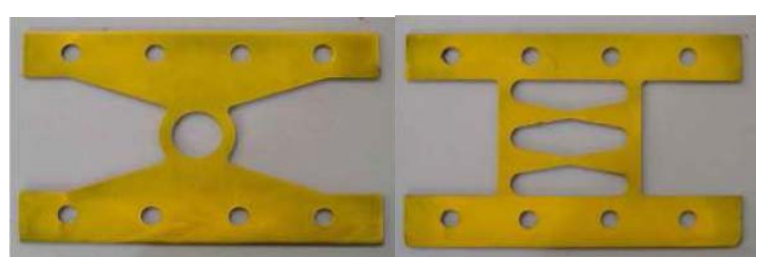

d.
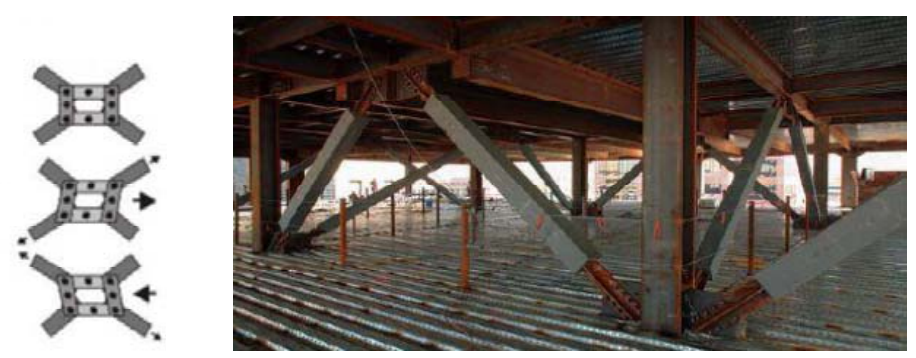

f.

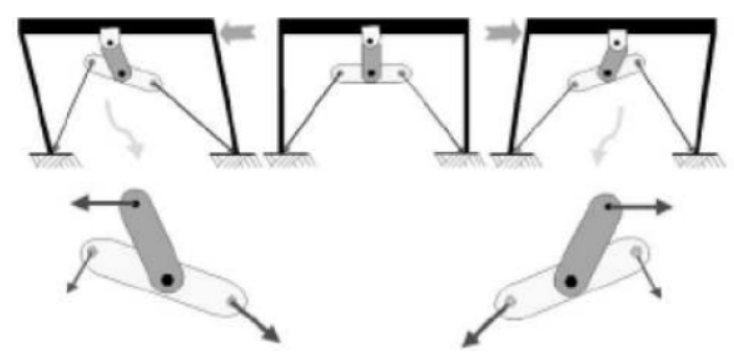

g.

Fig. 2 - Seismic dampers: a) honeycomb damper; b) TADAS; c) ADAS; d) DFMD; e) Pall; f) BRB; g) Damptech [3-7]. 
One disadvantage of most seismic dampers is that they are visible inside the structure. For example, the honeycomb damper, ADAS (Added Damping And Stiffness), TADAS (Triangular plate Added Damping And Stiffness), BRB (Buckling Restrained Brace), DFMD ("Dual Function" Metallic Damper), Pall and Damptech presented in Figure 2 are mounted in the structure by the means of bracings occupying the space within a frame. In order to solve these problems, the author proposes a new type of seismic damper called "Energy Dissipative Column" or EDC. The concept of "Energy Dissipative Column" is new in Civil Engineering, where columns are designed to be acted in the elastic domain and the energy dissipation occurs in secondary elements specially designed for this purpose. EDC solve this problem by absorbing the seismic energy within the column itself, through different mechanisms: either by plastic deformation of steel or by dry friction. This is achieved by targeting the plastic deformation on special dissipative elements mounted on the ends of the dissipative columns. After a major earthquake these elements can be replaced.

\section{Experimental model}

The proposed device is an energy dissipative column. Energy dissipation is achieved by plastic deformation of certain elements placed at the extremities. The central element of the column is unaffected during an earthquake.

The column is intended to be used in structures with Slimdek composite floors or flat slabs or in structures where plastic hinges cannot form in the beams. It has the following advantages:

- it can overtake gravitational loads when the dissipative elements lose their structural integrity after a major earthquake,

- it has multidirectional seismic energy dissipation capacity,

- it restricts the relative displacements of the level,

- the replacement of damaged dissipative elements is possible and with low costs.

The column consists of the following elements: a central element $-\mathrm{A}$, two dissipative elements $-\mathrm{B}$ and two metal plates $-\mathrm{P}_{\mathrm{i}}$ and $\mathrm{P}_{\mathrm{s}}$. The dissipative elements (B) are designed to absorb the seismic energy and to attach the column to the structure. These elements can be provided with holes of various shapes and sizes to ensure a good distribution of plastic deformations in the entire element.

The two metal plates were added to attach the model to the shaking table at the bottom and to a reinforced concrete plate at the top. The lower plate is denoted by $\left(\mathrm{P}_{\mathrm{i}}\right)$ and the upper one with $\left(\mathrm{P}_{\mathrm{s}}\right)$. The elements are joined together with M12 bolts, 10.9 strength class.

The central element (A), according to Figure 3, consists of:

- a central element (1) made of circular hollow section profile with the following dimensions: $114 \times 8 \mathrm{~mm}[8]$,

- two $20 \mathrm{~mm}$ thick steel plates denoted by (2),

- two elements (3) made of steel, with a cylindrical shape, $50 \mathrm{~mm}$ diameter, designed to overtake the gravitational loads and to create the double hinged supports of the column.

The dissipative element (B) consists of:

- a central element (4) made of circular hollow section profile with the following dimensions: $114 \times 4 \mathrm{~mm}$ [8], provided with holes to ensure the formation of plastic zones in case of lateral displacements caused by earthquakes,

- two $8 \mathrm{~mm}$ thick steel plates (5).

The element $\left(\mathrm{P}_{\mathrm{i}}\right)$, according to Figure $4 \mathrm{a}$, consists of:

- one element (6) made of $20 \mathrm{~mm}$ thick steel plate, 
- $\quad$ one element (7) made of steel, with cylindrical shape.

The element $\left(\mathrm{P}_{\mathrm{s}}\right)$, according to Figure $4 \mathrm{~b}$, consists of:

- one element (8) made of $20 \mathrm{~mm}$ thick steel plate,

- $\quad$ one element (7) made of steel, with cylindrical shape.
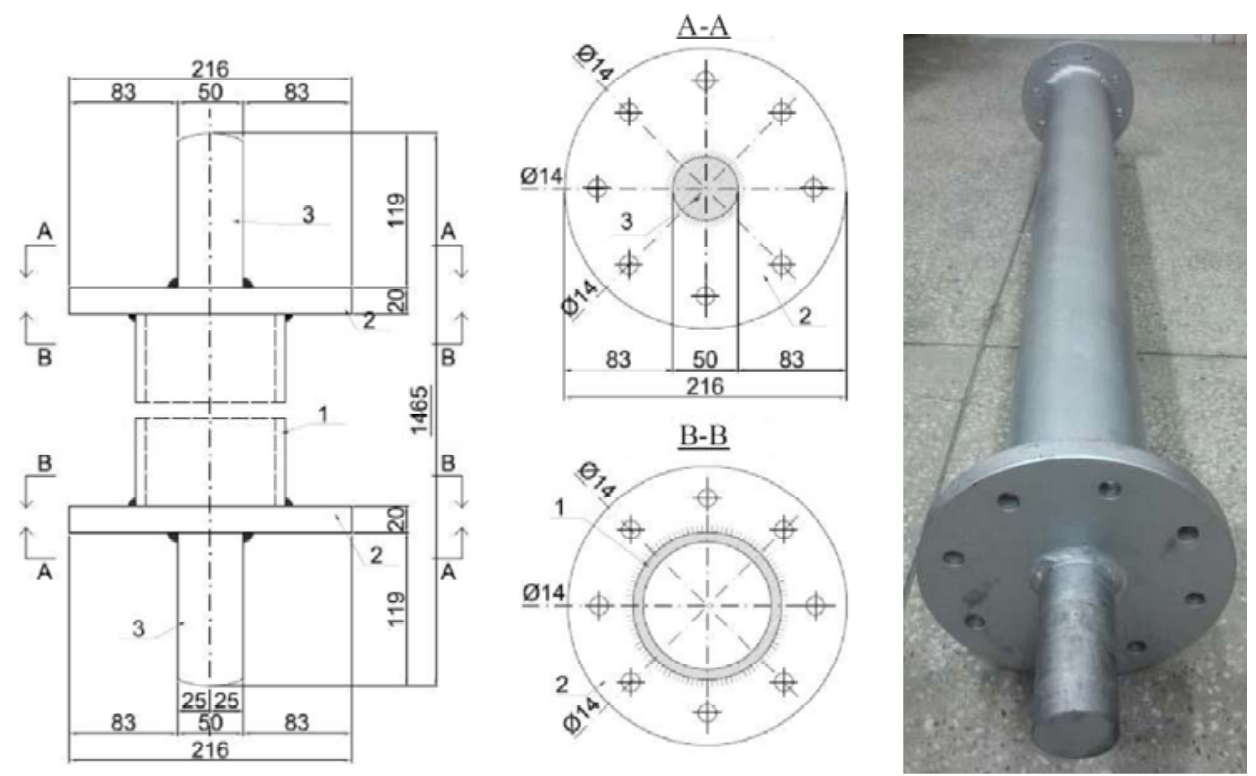

Fig. 3 - Central element (A) - geometrical dimensions and overall view of constructed element.

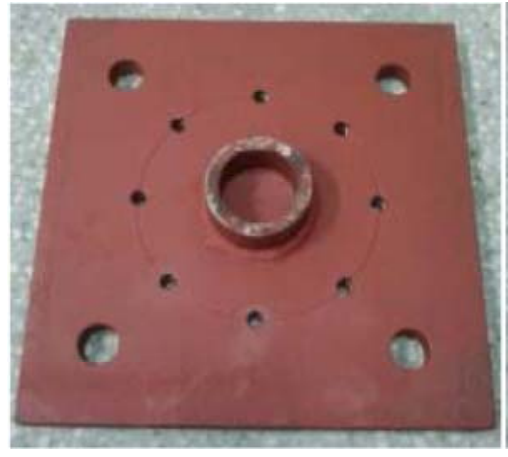

a.

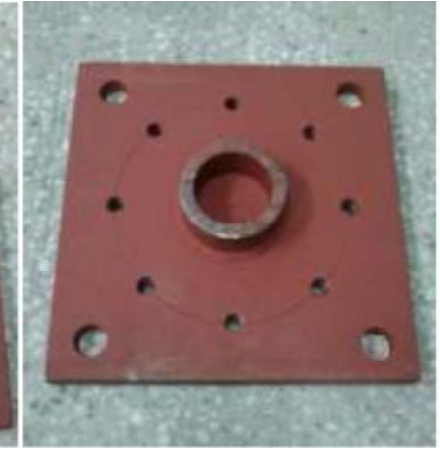

b.

Fig. 4 - Overall view of the metal plates: a) $P_{i}$ and b) $P_{s}$.

The experimental program consists of analysing a set of models at 1:2 scale, made of 4 energy dissipative columns and a concrete slab. The concrete slab is designed to simulate the behaviour of a flat slab or a Slimdek composite floor. The slab has the following dimensions: 160x160x24 cm.

The dissipative elements have the following characteristics: 6 rows of 16 circular $10 \mathrm{~mm}$ diameter holes, as shown in Figure 5.
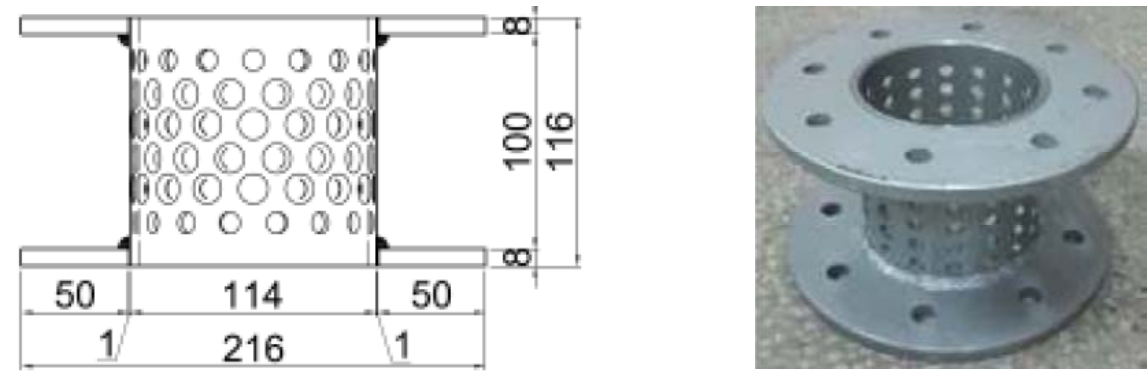

Fig. 5 - Dissipative elements (B) - geometrical dimensions and overall view of constructed element. 
The model was equipped with two types of transducers to acquire the experimental data on the action and response of the experimental model. Four displacement transducers ( 2 at the upper part and 2 at the lower part of the model) and four accelerometers (mounted in the same manner) were used. The transducers are calibrated following the procedures provided by the manufacturer and then mounted on the experimental model, as shown in Figure 6.

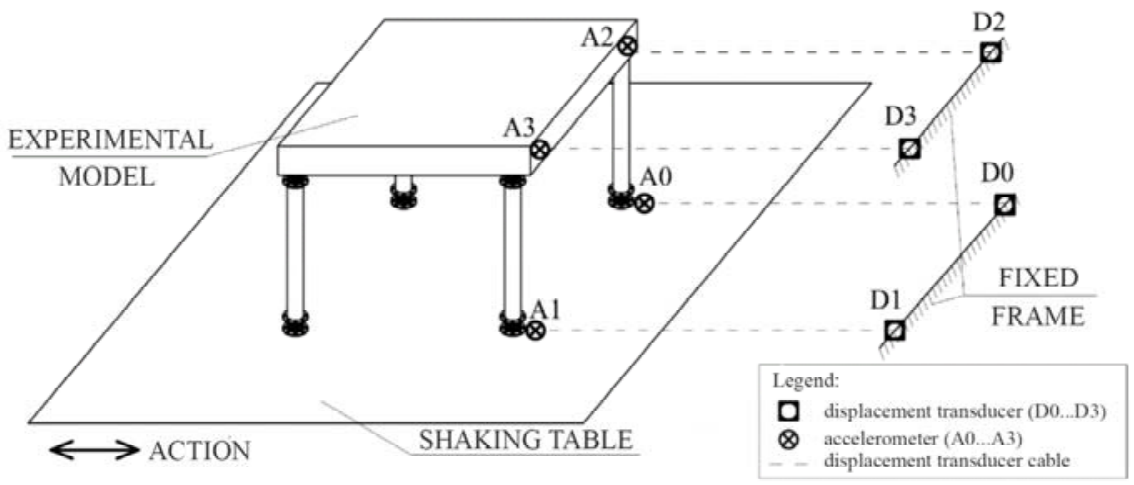

Fig. 6 - Experimental model with mounted transducers.

The damping factor for the experimental model was also determined using Equation (1).

$$
\xi=\frac{\Lambda}{2 \pi}=\frac{\ln \left(\frac{A_{i}}{A_{i+1}}\right)}{2 \pi}
$$

where:

$\xi$ is the damping factor,

$\Lambda$ - logarithmic decrement,

$$
\frac{A_{i}}{A_{i+1}}-\text { ratio between two successive amplitudes }[9,10] \text {. }
$$

The results are presented as hysteretic loops (relative displacement - absolute acceleration). These values are computed using Equations (2) and (3).

$$
\begin{aligned}
& D_{\text {rel }}=\frac{D_{2}+D_{3}}{2}-\frac{D_{0}+D_{1}}{2} \\
& a_{a b s}=\frac{A_{2}+A_{3}}{2}
\end{aligned}
$$

where:

$D_{\text {rel }}$ is the relative displacement,

$D_{2}, D_{3}$ - displacements recorded by the top transducers,

$D_{0}, D_{1}$ - displacements recorded by the bottom transducers,

$a_{a b s}-$ absolute acceleration,

$A_{2}, A_{3}$ - accelerations recorded by the top accelerometers.

\section{Experimental tests and results}

The natural frequency of vibration of the experimental model is equal to $5 \mathrm{~Hz}$ (as shown in Figure 7). Several tests were conducted considering a sinus beat action. Two tests were taken 
into consideration: test 133 and test 153 . The applied action during both tests is a beat sinus at a constant frequency of $5 \mathrm{~Hz}$ and an acceleration value equal to $0.6 \mathrm{~g}$ (as shown in Figure 8).

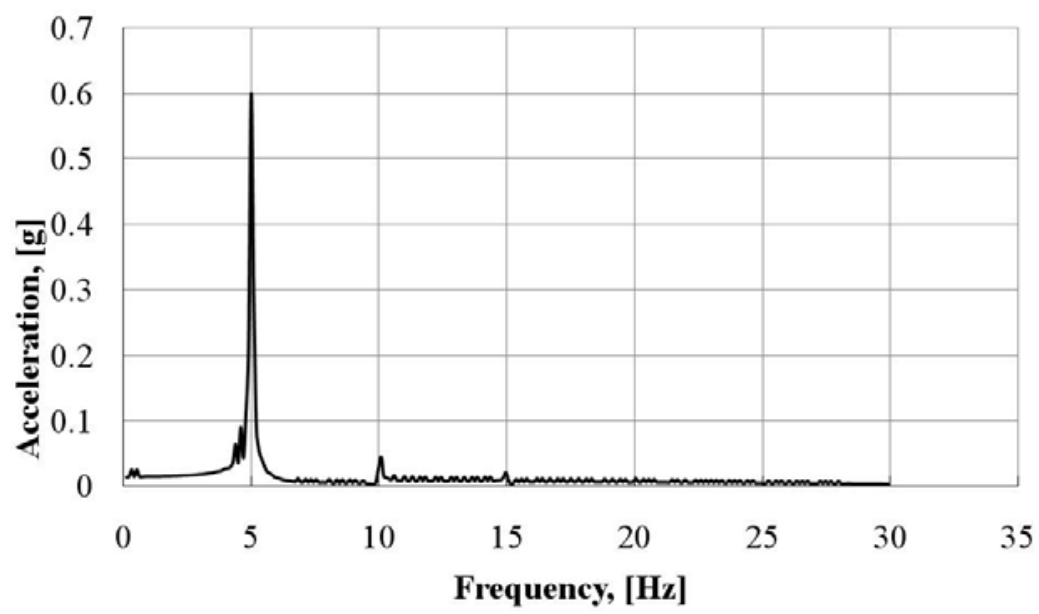

Fig. 7 - Experimental model natural frequency of vibration.

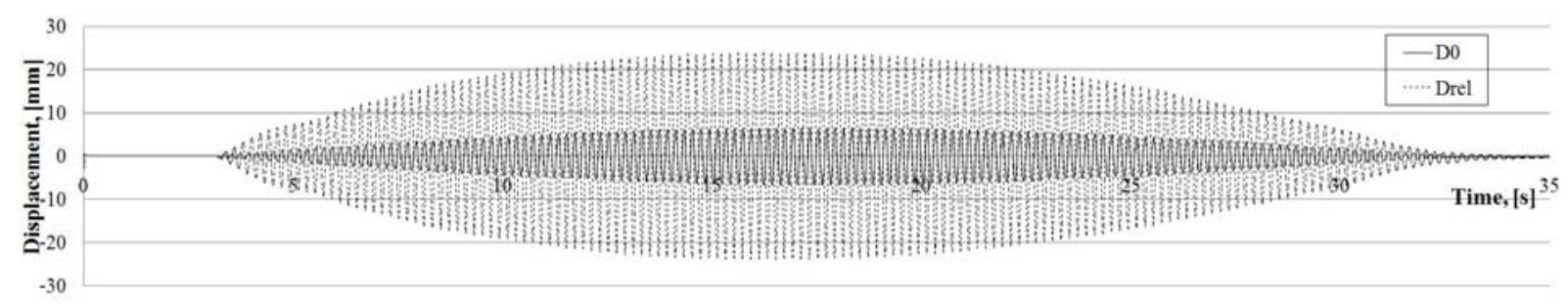

Test 133

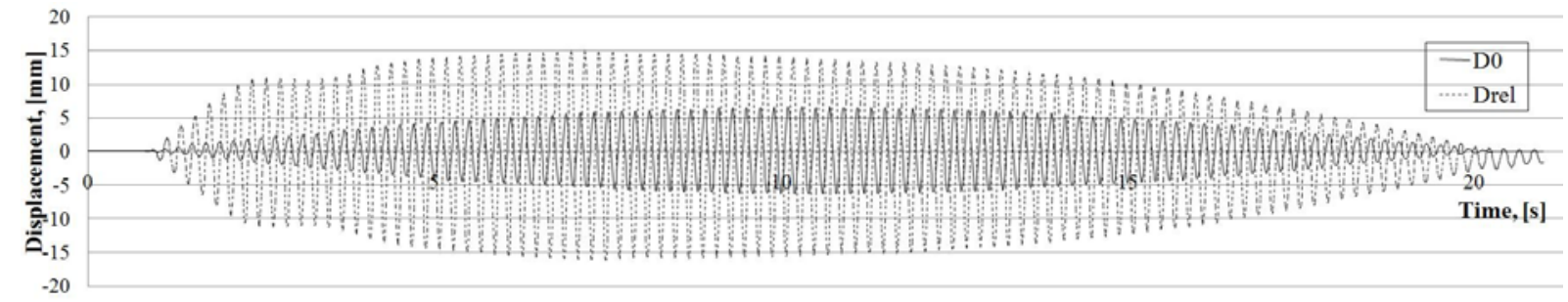

Test 153

Fig. 8 - Action $\left(D_{0}\right)$ and response $\left(D_{\text {rel }}\right)$ of the model for tests no. 133 and 153.

The plastic deformations and cracks developed in the dissipative elements are shown in Figure 9. The damages occurred in two upper dissipative elements.

After the testing, the natural frequency of vibration of the model decreased indicating its degradation and the central element of the columns did not show any signs of degradation. The damping factor of the model, computed according to Equation (1), is equal to 0.028.
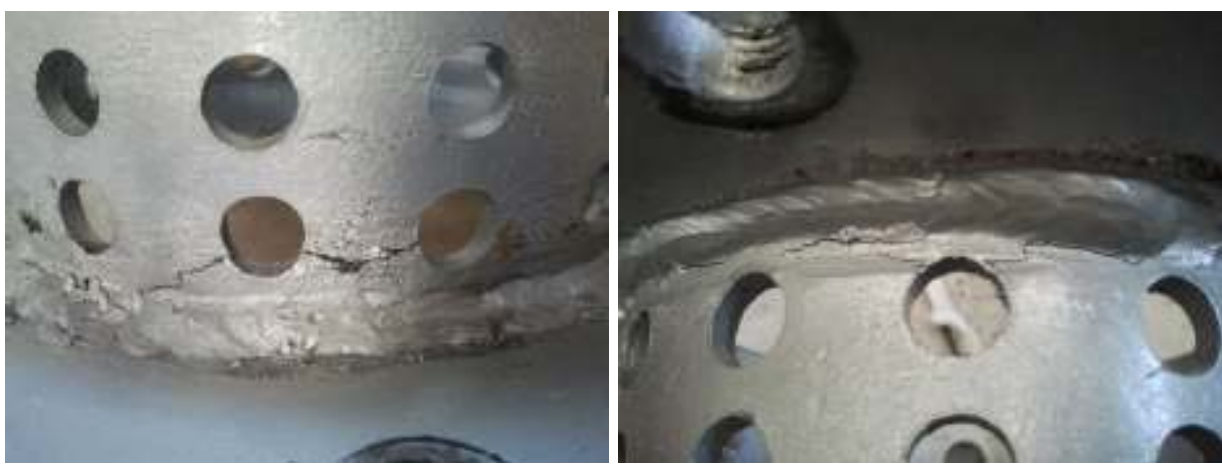

a) 

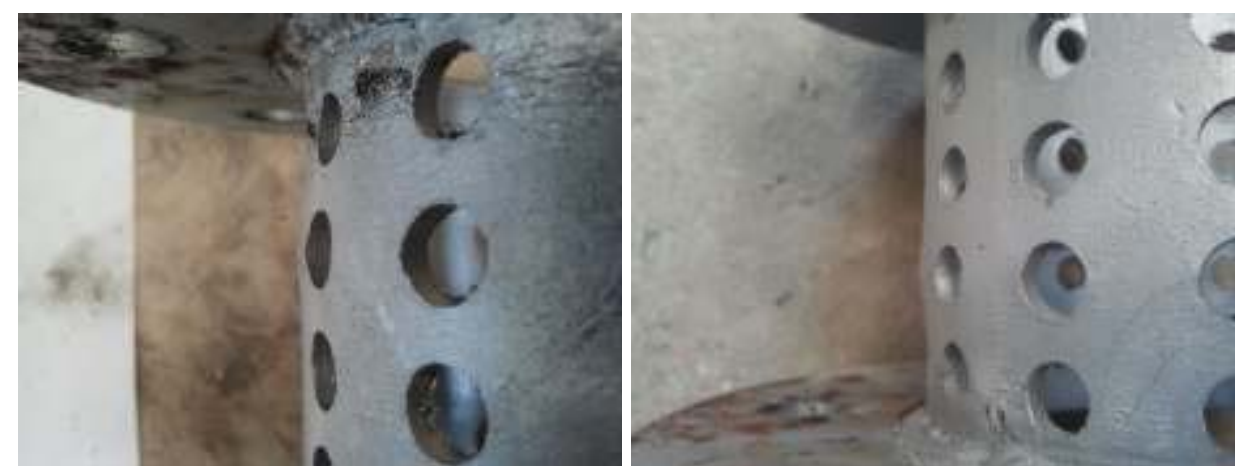

b)

Fig. 9 - Degradations on the dissipative elements: a) cracks, b) plastic deformations.

The most relevant method of representing the dissipating behaviour of a seismic damper is the hysteretic loop. It graphically represents the relationship between force and displacement, stress and strain or moment and curvature [11]. In this case the hysteretic loops are plotted using displacements and accelerations as shown in Figure 10.

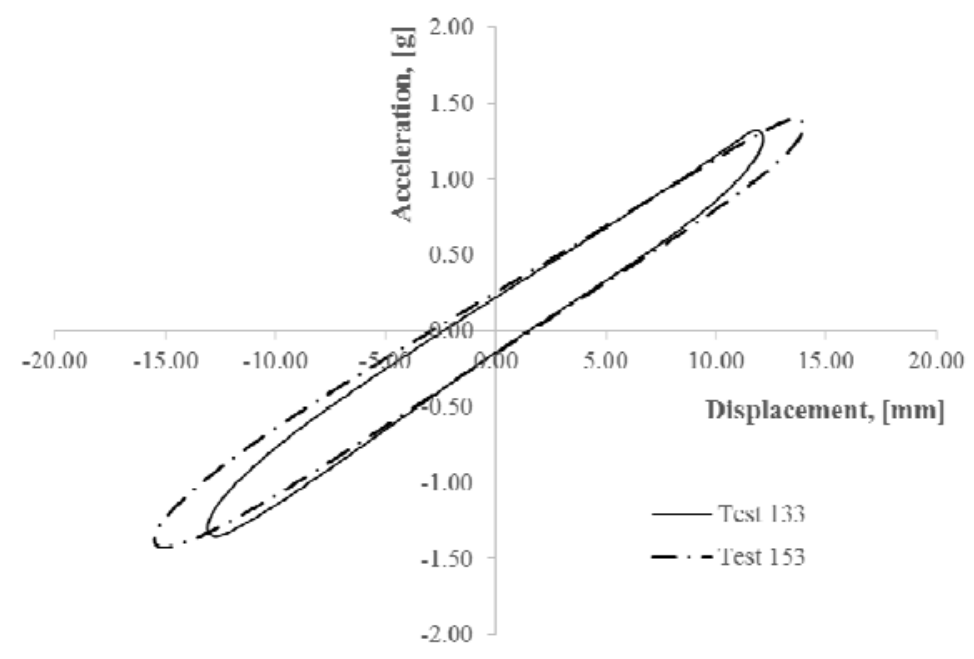

Fig. 10 - Hysteretic loops for the experimental model.

\section{Conclusions}

The hysteretic curves obtained from these tests describe a good energy dissipation capacity and predictable behaviour of these devices. Following a visual inspection of all the components at the end of the experimental testing it can be concluded that degradations were successfully targeted on the dissipative elements. The central element and the fasteners retained their structural integrity.

In conclusion, the energy dissipative columns are a good solution for the anti-seismic protection of structures with Slimdek composite floors or with flat slabs. The advantages of these devices are: high seismic energy dissipation capacity, capacity of overtaking the gravitational loads when the dissipative elements have lost their structural integrity, the damaged dissipative elements can be replaced after a major earthquake and the capacity of restricting level displacements.

\section{Acknowledgements}

The paper was presented at the "5th National Conference on Earthquake Engineering and the 1st National Conference on Earthquake Engineering and Seismology", June 19-20 2014, Bucuresti"; it was published in the volume of the Conference. 


\section{References}

[1]. Rackham, J. W., Couchman, G. H., Hicks, S. J. (2009). Composite Slabs and Beams using Steel Decking: Best Practice for Design and Construction (Revised Edition). The Steel Construction Institute and The Metal Cladding \& Roofing Manufacturers Association, ISBN: 978-1-85942-184-0, UK.

[2]. http://www.steelconstruction.info/images/c/c6/Slimdek.jpg

[3]. Budescu, M. (2005). Noi concepţii privind protecţia seismică a structurilor. Iaşi: „Matei-Teiu Botez” Academic Society Publishing House, ISBN 973-7962-81-8 (in Romanian).

[4]. Li, H. N., Li, G. (2007). Experimental study of structure with dual function metallic dampers. Engineering Structures, 29(8), 1917-1928, DOI: 10.1016/j.engstruct.2006.10.007.

[5]. Li, H., Huo, L. (2010). Advances in structural control in civil engineering in China. Mathematical Problems in Engineering, 2010, ID 936081, Cairo: Hindawi Publishing Corporation.

[6]. http://www.corebrace.com/new-temp-images/morebraces.jpg

[7]. Agyei - Agyemang, A. (2010). Impact Attenuation System Using a Passive Damper, Unpublished doctoral dissertation, Kwame Nkrumah University of Science and Technology, Faculty of Mechanical and Agricultural Engineering, Department of Mechanical Engineering, Knust - Kumasi, Ghana.

[8]. Asociaţia de standardizare din România (ASRO). (1980). Țevi din oţel, fără sudură, laminate la cald pentru construcţii, STAS 404/2-80, Bucureşti (in Romanian).

[9]. Elmenshawi, A., Sorour, M., Mufti, A., Jaeger, L. G., Shrive, N. (2010). Damping mechanisms and damping ratios in vibrating unreinforced stone masonry. Engineering Structures, 32(10), 3269-3278, DOI: 10.1016/j.engstruct.2010.06.016.

[10]. Val, D. V., Segal, F. (2005). Effect of damping model on pre-yielding earthquake response of structures. Engineering Structures, 27(14), 1968-1980, DOI:10.1016/j.engstruct.2005.06.018.

[11]. Ștefancu, A. (2011). Creșterea siguranţei construcţiilor din zone seismice utilizând sisteme pasive de disipare, Unpublished doctoral dissertation, „Gheorghe Asachi” Technical University of Iași, Faculty of Civil Engineering and Building Services, Iași, Romania (in Romanian). 